\title{
Imagem e memória na auto- ficção de Caio Fernando Abreu
}

\author{
NELSON LUÍS BARBOSA
}

"Minha vida está nos meus livros. Não há na minha história muitos fatos externos à obra que escrevi, porque o ponto de partida de tudo sempre foi pessoal demais."

(Caio Fernando Abreu)

“Tudo que não invento é falso.”

(Manoel de Barros)

\section{Uma obra confessional, sim, mas ficcional!}

$\mathrm{O}$ TOM confessional que desponta na obra do escritor gaúcho Caio Fernando Abreu (1948-1996), por certo aprendido de sua musa Clarice Lispector, levou a crítica muitas vezes a classificá-la como "autobiográfica", a despeito de o autor sempre ter declarado jamais ter sido esse seu interesse, embora tenha reconhecido abertamente que sua vida sempre esteve toda contida em sua obra. De fato, Caio jamais se furtou a viver experiências típicas de sua geração e a retratá-las em sua obra - viveu clandestino na Europa, foi lavador de prato, modelo vivo, hippie, dark, experimentou drogas etc. - e fez de sua vida uma sequência de entregas corajosas de sua intimidade, como o fato de logo ter se assumido homossexual numa época em que isso ainda não era comum, sobretudo nas letras, o que de certa forma contribuiu para que sua escrita espelhasse essa identidade e fosse recebida como "literatura gay", revelando antes uma leitura redutora - e por vezes preconceituosa - de uma crítica que sempre insistiu em ver o autor e, em consequência, sua obra única e exclusivamente por esse prisma. Essa característica de uma suposta escrita autobiográfica parece ter sido ainda cristalizada para a crítica em razão de sua declaração, em agosto de 1994, por meio de suas crônicas nos jornais O Estado de S. Paulo e Zero Hora, ser portador do vírus da imunodeficiência humana - mais uma entrega corajosa -, a temida Aids, da qual acabaria vítima menos de dois anos depois.

Esses fatos reais e biográficos - ou esses "biografemas", ${ }^{1}$ nas palavras de Roland Barthes - por certo enformaram a obra de Caio, pois, de um modo ou de outro, atravessam sua escrita e se alojam explícita ou sorrateiramente em seus muitos contos, novelas, seus dois romances, sua dramaturgia e, sobretudo, em suas crônicas, revelando do autor talvez mais do que ele mesmo pudesse ter pretendido mostrar. É possível adiantar que essa realidade perscrutada em sua escrita revela de certo modo, em Caio, uma crença de que a literatura pudesse 
de algum modo suprir as deficiências do real, sempre inferior ao imaginário, funcionando para ele como uma espécie de espelho onde pudesse enfim se mirar, se revelar aos outros, ou mesmo permitir ao Outro se ver ou se revelar por meio dela. Mas, mais que isso, essa escrita revela em si a própria crise da representação literária ao expor a experiência do próprio autor/narrador como o elemento determinante de sua criação assumida em sua vivência real.

Esse aparente paradoxo marcado por essa insidiosa presença do autor em sua obra na verdade se dissolve, por um lado, ao se reconhecer que, de fato, Caio F. jamais se dedicou a contar em seus textos histórias estritamente reais de sua vida, pelo menos não exclusivamente do prisma de uma pretensa "autobiografia", tal como o gênero foi concebido pelo francês Philippe Lejeune na década de 1970 ao reconhecer que, para que haja uma escrita autobiográfica, o autor deve estabelecer com o leitor um "pacto de verdade", por meio do qual se comprometa a contar sua história ou mesmo fatos dela passíveis de serem comprovados na realidade. Esse "pacto de verdade", segundo Lejeune (2005), legitimaria assim para o leitor uma leitura embreada que o lançasse num campo de constatações reais do narrado, ao contrário do "pacto romanesco" que já antecipa ao leitor que, em todo romance, toda história então narrada não passa de uma ficção, de uma fabulação, por mais que verossimilmente tudo lhe possa parecer real.

Isso nos leva a perguntar, por sua vez, que, se o conceito e a prática da "autobiografia" assim compreendidos segundo os princípios de Lejeune não parecem suficientes para justificar a escrita de Caio F., ou pelo menos um conjunto considerável de sua obra, que critérios ou que conceitos deveriam ser então considerados para se compreender o fato de o próprio autor reconhecer que sua vida esteja toda contida em sua obra, o que, aliás, parece ser sentido tanto pela crítica como por seus leitores? A resposta talvez esteja justamente na sequência da discussão proposta para o gênero da "autobiografia" que culmina, até os nossos dias, na concepção da "autoficção", mas desta vez não mais como um gênero específico, e sim como procedimentos de criação que permitam compreender as inserções biográficas e reais do autor (Caio) em sua obra.

Na esteira da compreensão do critério do homonimato entre autor-narrador-personagem proposta para a autobiografia como condição de uma "escrita do eu", Serge Doubrovsky (2007), ainda por volta de 1977, vem preencher uma lacuna deixada por Lejeune em razão do aparente paradoxo criado pelo seu "pacto de verdade" em relação à compreensão da realidade da existência de um "romance autobiográfico", até então inconcebível por aquele crítico francês. É assim que Doubrovsky cria para sua própria obra não apenas o termo "autoficção", mas também sua teoria, ${ }^{2}$ compreendendo uma escrita que, embora baseada e espelhada na realidade vivida pelo autor, não abrisse mão de seu caráter de criação linguística em sua construção, ensejando um espaço para se revelar uma verdade existencial ainda que por meio de uma construção estritamente ficcio- 
nal. Já pelo final dos anos 1980, entre outros desdobramentos paralelos então avançados, o conceito de autoficção foi apropriado por outro estudioso francês, Vincent Colonna, que, propondo uma espécie de esgarçamento do conceito doubrovskiano, remonta a prática da autoficção ao primeiro século de nossa era, creditando seu protótipo a Luciano de Samósata em seu livro Uma história verdadeira. Abrindo mão da condição exclusiva do homonimato para identificação de uma escrita autoficcional, Colonna vai identificar quatro tipos específicos dessa escrita que compreendem: a) a autoficção "fantástica", congregando autores como Dante, Borges e Cyrano de Bergerac, na qual se constata que o autor transpõe sua identidade no irreal e a amplia para além dos limites humanos sem estabelecer correspondências entre a ficção e a biografia; b) a autoficção "especular", cujo centro não é forçosamente ocupado pelo autor, mas onde ele se imiscui enviesadamente multiplicando jogos de espelho e "mises-en-abyme", a exemplo de Ítalo Calvino em Se um viajante numa noite de inverno...; c) a autoficção "intrusiva", em que o autor se coloca à margem da intriga em que ele se torna narrador, comentador, como no caso de Balzac, Flaubert etc.; d) a autoficção "autobiográfica", em que o autor se faz herói da história, organizada em torno de sua própria existência, por vezes mesclando elementos documentais e fatos e nomes reais - concepção essa que mais se aproxima da autoficção de feitio doubrovskiano.

Ambas as concepções de autoficção, de Doubrovsky e de Colonna, e seus respectivos desdobramentos, permitem, assim, com propriedade para o nosso estudo, ${ }^{3}$ uma abordagem mais abrangente da obra de Caio Fernando Abreu, possibilitando ao leitor perscrutar a presença real do autor de forma determinante em seus textos, ainda que de modo decididamente ficcionalizado. Entretanto, se isso parece evidente em se tratando da condição de homonimato entre autornarrador-personagem para o caso da autoficção doubrovskiana, em razão das "pistas" deixadas pelo autor em seu próprio texto ou por elementos facilmente identificáveis pela compreensão de dados "peritextuais" segundo a formulação de Gérard Genette (1987), ${ }^{4}$ para o caso da autoficção nos moldes propostos por Vincent Colonna, em que não se prescinde diretamente do explícito homonimato, a dificuldade de identificação de um fato real então ficcionalizado parece abrir um precedente para que se duvide do narrado como parte do mundo real do autor, percebido meramente como um recurso ficcional da narrativa. Considerando, pois, esse impasse, propomos como forma de verificação do fato real, para esses casos, uma abordagem da obra pelo critério que aqui chamamos de "sobreposição" de textos, amparados na concepção dos "paratextos/ epitextos" genettianos. Esse critério de sobreposição implica o cotejamento e a aproximação de textos variados do próprio autor ou de outros que venham, de algum modo, informar e/ou recuperar o dado existencial, permitindo com isso a identificação de sua transposição no texto por meio da elaboração ficcional. Assim, por meio do diálogo estabelecido entre o texto-base (a obra ficcional) e 
outras formas de escrita, como cartas, crônicas, entrevistas, depoimentos etc., chega-se à identificação desse fato real transposto na criação ficcional do autor. Esse critério possibilita, entre outras coisas, o estabelecimento de uma autoficção mesmo para os casos de narrativas fortemente articuladas em uma potente terceira pessoa ou por outros modos de elaboração criativa por parte do autor, mesclando ora o recurso do homonimato, ora o recurso da sobreposição dos textos identificadores do elemento real transpassado na ficção.

Esse entrecruzamento entre ficção e vida real, proporcionado pela concepção da autoficção como processo e/ou procedimento de escrita, amparado ainda nessa "confluência" de gêneros verificável pelo critério da "sobreposição" de textos, parece revelar, para o nosso estudo, como bem aponta o crítico Marcelo Pen (2006, p.10),

que a vida de Caio não se deu tão-somente em torno de sua obra, mas dentro dela também. As pinceladas de vida que se percebem em sua literatura não se limitam à necessidade que ele sentia de explicar quase todos os seus textos, cercando-os como de uma moldura autoral; tampouco se restringe ao fato de haver um entrelaçamento entre trajetória artística e biográfica, imbricação que reflete a coragem do escritor de divulgar sua doença em suas crônicas [...] É outra coisa. Mais ainda do que o que ocorre com Clarice Lispector, sua maior influência, ou com Hilda Hilst, a suposta personalidade de Caio imiscui-se em suas criaturas, a ponto de podermos dizer que o único personagem que ele jamais criou foi ele mesmo.

\section{“Oásis" - a memória refeita pela autoficção}

Dentre os muitos textos de Caio F. passíveis de uma leitura pautada pelos princípios da autoficção, em que se pode vislumbrar em especial a questão da imagem e da memória vazadas no texto, escolhemos para este breve estudo o conto "Oásis", de seu segundo livro de contos publicado em 1975, O ovo apunhalado. A opção pela leitura desse conto pretende também contribuir para se desfazer certo equívoco de parte de uma crítica desinformada que atribui a presença de Caio de modo mais incisivo em sua obra somente depois de sua comunicada contaminação pelo vírus HIV, como numa tentativa de transformar a Aids num tema determinante de sua escrita, bem ao estilo de narrativas in extremis, quando não ao gosto de uma especulação midiática que se compraz numa morbidez que definitivamente não foi vivenciada por Caio até sua morte em fevereiro de 1996.

Em linhas gerais, o conto se articula como a memória do narrador que relembra uma brincadeira de sua infância, criada entre os seus, chamada de "Oásis": tratava-se, na verdade, de um recurso encontrado pelos meninos para adentrarem o quartel que ficava no final da rua, e que os atraía pelos mistérios que se escondiam por detrás daqueles muros brancos que certa vez tiveram a oportunidade de visitar. A brincadeira consistia, pois, numa suposta queda de um avião em que eles viajavam em meio a um deserto perdido no mundo, que nada mais era que uma rua da cidadezinha da infância do narrador e de seus companhei- 
ros. Assim, forjava-se a necessidade de caminharem pelo deserto em busca do quartel (oásis) onde por certo encontrariam materiais e peças necessários para o conserto do avião para prosseguirem a viagem - viagem que, aliás, não compunha propriamente a brincadeira, mas sim o fato de ela ali ser interrompida, obrigando-os à busca dessas possíveis peças. O pacto de ficção assumido pelos meninos para que a brincadeira se desse de modo insofismável funcionava como uma regra de ouro impossível de ser quebrada, pois não lhes bastava apenas a sugestão de estarem perdidos num deserto com o avião em pane e em busca de uma ajuda fantástica que pudesse fazê-los encontrar a referida peça para consertar o avião. Tudo havia de ser absolutamente crível, a ponto de a brincadeira não poder acontecer após um dia chuvoso, por não suportarem a ideia de ter de rastejar em meio a lamaçais e cinamomos verdes e aguados, e ter de acontecer impreterivelmente em dias de sol escaldante, para que ficassem completamente empapados de suor e pudessem sentir realmente sobre suas cabeças "aquela massa amarela quase esmagando os miolos" (Abreu, 1975, p.19). E o narrador em primeira pessoa assim explica a brincadeira:

Brincar de oásis era a senha, e imediatamente nos aprumávamos: caíamos no chão, ainda desacordados com o choque produzido pela queda do avião onde viajávamos, depois lentamente abríamos os olhos e tateávamos em volta, no meio da rua, tocando as pedras escaldantes da hora de sesta. Quase sempre Jorge voltava a fechar os olhos, dizendo que preferiria morrer ali mesmo do que ficar dias e dias se cansando à toa pelo deserto; e quase sempre eu apontava para o arco do fim da rua dizendo que se tratava de um oásis, que meu avião já havia caído ali uma vez e que, enfim, tinha certa experiência de caminhadas no deserto; em seguida Luiz investigava os bolsos e apresentava algum biscoito envelhecido, acrescentando que já tínhamos víveres suficientes para chegar até lá. Convencido Jorge, tudo se passava normalmente. (ibidem)

O rastejar-se sob o sol forte prosseguia assim pelas ruas da cidadezinha dos meninos que iam cuidadosamente ignorando casas e muros, ou mesmo projetando-os como imagens de pedras e de deserto aberto, até que sinais dessa civilização real se perdessem em cercas de arame farpado que chegavam ao arco do fim da rua onde se encontrava o portal do quartel, o ponto culminante da dura caminhada. Nesse trajeto inóspito e seco, qualquer possibilidade de quebra do pacto ficcional assumido entre eles era tomada como uma traição, tal como certa vez aconteceu com Jorge que, de tanta sede real que a ficção lhe trouxera, se rendeu a pedir um copo de água a uma mulher que a eles assistia curiosa da janela de sua casa. Diante do olhar indignado dos companheiros pela flagrante traição, o menino, com a água ainda pingando do queixo, recompõe a ficção justificando com legitimidade: "Foi uma miragem".

Como a brincadeira se repetia naqueles dias de seca intensa, não demorou para que os meninos acabassem conquistando a amizade de um guarda do portão do quartel que, seduzido por eles com promessas e bilhetes que forjavam um interesse amoroso em relação a ele por parte de Dejanira, a empregada da casa, 
franqueava-lhes a entrada no quartel, naquele mundo estranho ao narrador, para quem "tínhamos certeza de estarmos lentamente ingressando numa espécie de sociedade mágica e secreta" (ibidem, p.21). Foi assim que, numa tarde não determinada no conto, diante do portão do quartel estranhamente sem guarda, já acostumados aos passeios internos sem serem incomodados, os meninos adentraram o local em busca da fantástica peça necessária à fantasia do conserto do avião. De início, observaram o movimento incomum no quartel: "carroças se chocavam, armas passavam de um lado para outro, soldados corriam e gritavam palavrões, o chão estava sujo de esterco, os cavalos todos enfileirados" (ibidem, p.22). Incógnitos em meio ao movimento estranho do quartel, foram parar numa sala onde, até então, jamais haviam entrado:

Examinamos as paredes vazias, depois descobrimos, num canto, sobre uma mesa, um estranho aparelho cheio de fios. Talvez estivesse ali o grande segredo. Luiz, o mais afoito, começou a mexer nos fios, Jorge descobriu um microfone e por algum tempo ficamos ali parados, sem compreender exatamente o que era aquilo, mas certos de que se tratava de uma peça importantíssima para o funcionamento de toda a organização. (ibidem)

Nesse ambiente desconhecido, foram surpreendidos por dois soldados estranhos, com fardas diferentes e penduricalhos nos ombros, que se lançaram sobre eles, sacudindo-os: "Falavam os dois ao mesmo tempo, aos berros, depois, com mais alguns trancos, jogaram-nos num canto. Um deles, de bigode enorme, avançou para nós e, com uma voz que me pareceu completamente hedionda, disse que ficaríamos presos até aprendermos a não nos meter onde não era de nossa conta" (ibidem). A façanha dos meninos provocou nos estranhos guardas o desejo de aplicar-lhes um castigo exemplar, e assim eles foram trancados numa pequena sala, suja, fria, "com uma janela gradeada na altura do teto", a despeito do tórrido calor do lado de fora: "Ficamos ali durante muito tempo, incapazes de dizer qualquer palavra, num temor tão compacto que não era preciso evidenciá-lo. Jorge chorava, eu e Luiz nos encolhíamos contra as paredes" (ibidem). O terrível confinamento durou até a noite, quando por fim o soldado amigo irrompeu na sala libertando-os daquela prisão e levando-os de volta para casa em um jipe militar: "Mamãe estava descabelada, as vizinhas todas em volta, as luzes acesas: entramos na sala pela mão do soldado, que falou rapidamente coisas que não conseguimos entender enquanto todo mundo nos envolvia em beijos e abraços, logo contidos quando perceberam meu estado lastimável" (ibidem, p.23).

O desaparecimento dos meninos, mas também o fato que causara esse desaparecimento desencadearam no ambiente familiar uma forte desagregação, a ponto de as acusações de culpas partirem de todos os lados, colocando pai contra mãe, mãe contra pai, os pais contra a empregada e vice-versa:

Dejanira disse que não ficava mais nem um minuto naquela casa de doidos; papai disse que mamãe não nos dava a mínima; mamãe disse que era uma verdadeira escrava; papai disse que não podia dar atenção a seus chiliques na hora 
em que o país atravessava uma crise tão difícil - e acabaram os três gritando tão alto quanto os dois soldados de farda diferente, com penduricalhos coloridos nos ombros. (ibidem, p.23)

Depois de verem a empregada Dejanira deixar a casa resmungando desaforos, depois de algumas chineladas e da vara de marmelo, as crianças foram postas na cama sem jantar. O parágrafo final do conto sintetiza, assim, a imagem do ocorrido na mente da criança narradora:

Ficamos muito tempo acordados no escuro, ouvindo o som do rádio que vinha da sala e os passos apressados na rua. Antes de dormir ainda ouvi a voz de Jorge perguntando a Luiz o que era uma revolução, e um pouco mais tarde a voz de Luiz, apagada e hesitante, dizer que revolução era assim como uma guerra pequena. Mais tarde, não sei se sonhei ou se pensei realmente que os aviões não caíam no meio das ruas, e que as ruas não eram desertos, e que portões brancos de quartéis não eram oásis. E que mesmo que portões brancos de quartéis fossem oásis e cinamomos pintados de branco até a metade fossem palmeiras, não se encontraria nunca uma peça de avião no meio de duas palmeiras [...] E por todas essas coisas, creio, soube que nunca mais voltaríamos a brincar de encontrar oásis no fim das ruas. Embora fosse muito fácil, naquele tempo. (ibidem, p.24)

A posição do narrador no conto permite constatar tratar-se de sua memória não apenas de uma brincadeira do tempo de sua infância perdida, mas em especial de um fato único ocorrido numa dessas ocasiões, e que definitivamente pôs fim àquela brincadeira dos meninos. Ainda que esse fato específico não seja tão diretamente explicitado no conto, é possível perceber tratar-se do golpe militar articulado nos quartéis brasileiros na passagem do dia 31 de março para $1^{\circ}$ de abril de 1964, que por força das imposições militares passou para a história nacional como a "revolução de 64". O termo "revolução" aparece recuperado no conto tanto pela óptica do pai, ao reconhecer que o país atravessava uma difícil crise, como também das crianças em castigo, certamente ao retomarem o termo do noticiário vazado pelo rádio da sala repercutido no quarto em que elas ficaram confinadas pela segunda vez no dia, depois da desagregação familiar que em muito reproduzia a própria voz alterada e violenta dos soldados nas dependências do quartel.

O conto funcionaria assim como uma legítima narrativa ficcional que recupera pela memória do narrador a imagem de um fato histórico comum a grande parte dos brasileiros, não somente pelo desconhecimento efetivo do que estava se arquitetando no país naqueles idos de 1964, mas também, e propriamente, pela sensação de perda de inocência e pelo reconhecimento de realidades mais duras dali em diante, impostas por uma ditadura militar que solaparia as bases de uma cultura ainda em construção e, desde então, banida da vida nacional.

Dizemos que o conto "funcionaria" como uma narrativa ficcional não fossem alguns elementos contidos na sua construção e no seu peritexto que possibilitam ao leitor recuperar dados de uma realidade do autor/narrador que 
podem ser comprovados no plano do real, e que, portanto, permitem afirmar, sem erro, que o narrador em primeira pessoa é o próprio autor Caio Fernando Abreu. Referimo-nos aqui à dedicatória do conto, até então omitida, que assim se apresenta: "Para José Cláudio Abreu, Luiz Carlos Moura e o negrinho Jorge". Essa dedicatória remete diretamente a pelo menos dois dos personagens do conto explicitamente citados no corpo do texto: Luiz e Jorge, respectivamente o primo do autor, conhecido como Beco (conforme informado na biografia do autor escrita por Callegari (2008, p.22), e pela própria irmã de Caio, Cláudia Abreu, em depoimento para nosso estudo), e o menino Jorge, afilhado da mãe de Caio, que, juntamente com o irmão de Caio, apelidado Gringo (José Cláudio Abreu), se lançavam costumeiramente a essas brincadeiras. Além da dedicatória, a relação de parentesco e amizade pode ser depreendida de uma carta do próprio autor à amiga Jacqueline Cantore datada de 24 de junho de 1981, enviada de São Paulo, onde Caio veio depois a morar (cf. Abreu, 2002, p.34). Nessa carta pode-se ler: "Véspera de São João, e a minha cabeça deu uma volta até as fogueiras que nós fazíamos em Santiago do Boqueirão, eu, Nairzinha, minha irmã de criação, Beco, meu primo, o negrinho Jorge, afilhado de minha mãe, meu irmão Gringo..." (ibidem), passagem em que o autor recupera uma das brincadeiras do tempo de infância e identifica entre os amigos os personagens do conto ora em estudo.

Esse dado biográfico, pelo vínculo real existente entre os personagens e o narrador - que facilmente estabelece o homonimato entre autor/narrador/personagem do conto -, como também a confirmação dessas brincadeiras explicitada na carta autoral e no depoimento da irmã de Caio permitem a compreensão de que o autor efetivamente narra em seu conto uma experiência real do tempo de menino, vivida na sua Santiago do Boqueirão de sua infância, cidade "polvilhada de quartéis" (Callegari, 2008, p.19). O pai de Caio, aliás, fora militar, e o quartel descrito no conto de fato ficava a poucas quadras da casa paterna onde o menino Caio viveu até os seus quinze anos de idade, rodeado de irmãos, primos e amigos.

Se a brincadeira de menino assim contada se nos apresenta, em princípio, como um dado real - o que também explica aquela necessidade de as crianças forçarem o elemento ficcional de sua brincadeira para que tudo parecesse ainda mais "real" -, o estatuto da realidade não necessariamente pode ser atribuído ao fato principal ocorrido naquele determinado dia da brincadeira. Reconhece-se, assim, que no ano de 1964, quando do golpe militar, Caio F. contava, então, já com quase dezesseis anos de idade, e já não vivia mais em Santiago do Boqueirão, e sim em Porto Alegre, para onde fora enviado pelos pais para estudar no Instituto Porto Alegre (IPA), como dados de sua biografia podem confirmar. Além disso, seria pouco provável que um menino de dezesseis anos, mesmo naquela época, ainda se lançasse a brincadeiras desse tipo com os colegas. Essa constatação também se infere do próprio texto do conto, pois o narrador conta 
que os meninos, ainda muito pequenos, eram banhados pela empregada da casa, ocasião em que melhor se apropriavam de histórias da empregada para depois negociá-las com o guarda do portão do quartel que se acreditava enamorado dela tão somente pelos bilhetes falsos que os meninos forjavam com confissões de amor e carinho.

Percebe-se assim que o conto, pela sua estrutura autoficional, apresenta uma natureza híbrida composta, segundo Umberto Eco (2006, p.126), de uma narrativa natural e de uma narrativa artificial, em que a primeira descreve fatos que ocorreram na realidade, enquanto a segunda "é supostamente representada pela ficção, que apenas finge dizer a verdade sobre o universo real ou afirma dizer a verdade sobre um universo ficcional". Nesse caso, identifica-se, na figura da empregada, o elemento de transição entre a narrativa natural e a artificial, uma vez que não há registro dessa personagem na instância da realidade do texto, conforme depoimento da irmã de Caio. Assim o conto se articula, por um lado, pela narrativa de fatos reais da própria vida de Caio, recuperados pela sua memória de uma infância feliz junto dos seus; e, por outro, por uma ficcionalização de um fato histórico que por certo viria marcar a vida do autor, mas não necessariamente pelo modo como se pode apreender no conto do ainda jovem Caio Fernando Abreu. De fato, por sua irreverência e ousadia, Caio fora depois vítima de ações da ditadura, tendo ainda na juventude, em Porte Alegre, certa vez, levado uma surra de capangas de um conhecido informante que, por agredir sua amiga Magliani com frases racistas e um bofetão, fora alvo da fúria de Caio que partiu para cima do rapaz. Além disso, já morando entre São Paulo e Rio, entre os anos 1969 e 1970, Caio chegou a passar temporadas na Casa do Sol, de Hilda Hilst, em Campinas, escondido da polícia política do Dops, tendo também alguns de seus textos censurados pela ditadura militar. $\mathrm{O}$ fato ocorrido no quartel, portanto, não poderia ter sido vivido realmente pelo autor ainda criança, e o período mais duro do estado ditatorial não se deu inicialmente nos primeiros anos após 1964, e sim com a decretação do AI-5, já em 1968 (cf. Süssekind, 2004, p.22-7), quando Caio já contava com vinte anos e até já vivia em São Paulo, compondo a primeira turma de jornalistas que trabalhavam na recém-criada revista Veja da Editora Abril.

No seu modo peculiar de mesclar ficção e realidade, vida e obra, Caio não se furtou a contar, ao seu modo e de maneira poética, e pela óptica de uma criança, um fato que também marcou sua vida de uma maneira especial. E toda a imagem da violência, da incomunicabilidade imposta, da prisão e da truculência relacionadas ao período da ditadura militar aparece nesse conto de modo sutil, pela história inocente vivida pelas crianças. Observe-se que o conto tangencia também a situação de desagregação familiar vivida nos períodos mais difíceis da ditadura e retrata sobretudo o momento da perda da inocência não só do autor, mas também de sua geração.

É nesse sentido que se pode dizer que a autoficção de Caio se organiza 
a partir de sua própria vivência, mas que nem por isso se compromete com uma realidade factual que a limite ou a transforme num relato eminentemente autobiográfico. E percebe-se que, lançando mão da autoficção, o autor recria sua história e a transforma, pela ficção, em memória de uma história real. Nas muitas vezes em que se dizia cansado das agruras da vida de escritor num Brasil tão miserável, Caio se ressentia do que considerava a inutilidade de escrever num país com tantas carências e necessidades materiais. Foi então que seu analista o convenceu de que todo escritor na verdade é um biógrafo da emoção, condição que lhe possibilita, mais do que o jornalismo e a imprensa, contar a verdadeira história de sua época. O incentivo lhe caiu tão bem que Caio, desde então, passou a ser também conhecido por esse apelido, "biógrafo da emoção", pela sua capacidade de tão bem contar, entre os melhores escritores de sua geração, a realidade e a condição do homem, sobretudo do seu tempo, e no Brasil.

Segundo Umberto Eco (2006, p.135), em sua sexta conferência intitulada "Protocolos ficcionais" que compõe seu livro Seis passeios pelos bosques da ficção, um fator que contribui para que uma obra de ficção possa ser projetada na realidade é a tendência que temos de "construir a vida como um romance". Eco (2006, p.137) percebe que a ficção nos fascina tanto porque

Ela nos proporciona a oportunidade de utilizar infinitamente nossas faculdades para perceber o mundo e reconstituir o passado. A ficção tem a mesma função dos jogos. Brincando as crianças aprendem a viver, porque simulam situações em que poderão se encontrar como adultos. E é por meio da ficção que nós, adultos, exercitamos nossa capacidade de estruturar nossa experiência passada e presente.

Com base nessas constatações, Eco (2006, p.137) se pergunta: "Mas, se a atividade narrativa está tão intimamente ligada a nossa vida cotidiana, será que não interpretamos a vida como ficção e, ao interpretar a realidade, não lhe acrescentamos elementos ficcionais?", para concluir:

De qualquer modo, não deixamos de ler histórias de ficção, porque é nelas que procuramos uma fórmula para dar sentido a nossa existência. Afinal, ao longo de nossa vida buscamos uma história de nossas origens que nos diga por que nascemos e por que vivemos. Às vezes procuramos uma história cósmica, a história do universo, ou nossa história pessoal (que contamos a nosso confessor ou a nosso analista, ou que escrevemos nas páginas de um diário). Às vezes, nossa história pessoal coincide com a história do universo. (ibidem, p.145)

Eco finaliza suas conferências expondo, pela comunicação de uma experiência real vivida por ele, os elementos fundamentais que compõem a complicada relação existente entre realidade e ficção e o modo como essas instâncias se articulam para maravilhar o homem capaz não somente de construí-la, mas também de vivê-la. Ele conta, por meio de uma narrativa natural, que, certa vez, ao visitar o Museu da Ciência de La Coruña, na Galícia, o curador fez-lhe uma surpresa extremamente agradável ao mostrar-lhe, na sala escura, o mesmo céu que aparecera sobre sua cidade natal - Alessandria, na Itália - na noite de 5 para 
6 de janeiro de 1932, quando de seu nascimento: "Quase hiper-realisticamente vivenciei a primeira noite de minha vida". Ele conta que sua emoção foi tanta, que teve "a sensação - quase o desejo - de que podia, deveria morrer naquele exato momento e que qualquer outro momento teria sido inadequado. Teria morrido alegremente, pois vivera a mais bela história que li em toda a minha vida". Esse céu, é claro, não fora contemplado efetivamente por ele mesmo, tampouco por sua mãe, e talvez tenha sido visto pelo seu pai "ao sair para o terraço, um pouco agitado com o fato maravilhoso (pelo menos para ele) que testemunhara e ajudara a produzir". E conclui assim sua experiência:

Talvez eu tivesse encontrado a história que todos nós procuramos nas páginas dos livros e nas telas do cinema: uma história na qual as estrelas e eu éramos os protagonistas. Era ficção, porque a história fora reinventada pelo curador; era História porque recontava o que acontecera no cosmos num momento do passado; era vida real porque eu era real e não uma personagem de romance. Por um instante, fui o leitor-modelo do Livro dos Livros.

Aquele foi um bosque da ficção que eu gostaria de nunca ter deixado.

Mas, como a vida é cruel, para vocês e para mim, aqui estou. (ibidem, p.147)

\section{Conclusão}

Como pudemos demonstrar nos limites propostos para este artigo, a escrita autoficcional de Caio Fernando Abreu desponta em sua obra desde os seus primeiros movimentos de escrita, antes mesmo de uma certa sistematização desse conceito literário, e atravessa sua vida e obra de um modo tão incomum na literatura brasileira que, pela sua própria condição de espectador de si mesmo, lhe permite, de modo absolutamente inusitado nas nossas letras, pela maneira como pôde viver seu próprio fim, inserir nelas também a sua própria morte. Talvez, e somente nesse sentido, fosse possível ler sua obra como "autobiográfica", à revelia de seu próprio desejo de assim tê-la composto. $\mathrm{O}$ modo como ele, por meio da autoficção, recompõe sua memória e recupera sua própria história corresponde muito facilmente à ideia da própria literatura como a concebe a crítica Leyla Perrone-Moisés (1990, p.102-4):

A literatura, felizmente, continua existindo, apesar de não acreditarmos mais na possibilidade de a linguagem representar ou expressar um real prévio, criar, inventar ou produzir um objeto que seja auto-suficiente ou, pelo contrário, reabsorvido e utilizado pelo real concreto. A literatura parte de um real que pretende dizer, falha sempre ao dizê-lo, mas ao falhar diz outra coisa, desvenda um mundo mais real do que aquele que pretendia dizer.

A literatura nasce de uma dupla falta: uma falta sentida no mundo, que se pretende suprir pela linguagem, ela própria sentida em seguida como falta [...] $\mathrm{Na}$ sua gênese e na sua realização, a literatura aponta sempre para o que falta, no mundo e em nós. Ela empreende dizer as coisas como são, faltantes, ou como deveriam ser, completas. Trágica ou epifânica, negativa ou positiva, ela está sempre dizendo que o real não satisfaz. 
Notas

1 Em linhas gerais, segundo Barthes, mínimos traços biográficos de um autor que resvalam para a sua obra.

2 Até muito recentemente, defendia-se que o termo "autoficção" aparecera pela primeira vez na quarta capa do romance Fils, de Doubrovsky. O estudo de Isabelle Grell (2007) sobre os manuscritos do romance abandonados por Doubrovsky, por exigência de sua editora, revela que o termo e sua conceituação, ao contrário, já apareciam no corpo do texto do autor, antes mesmo da conceituação da autobiografia por Philippe Lejeune, em 1975.

$3 \mathrm{O}$ artigo se baseia na tese de doutorado "Infinitivamente pessoal": a autoficção de Caio Fernando Abreu, o "biógrafo da emoção", defendida na FFLCH-USP em maio de 2009.

4 Gérard Genette (1987) identifica como elementos “peritextuais” todo dado informacional que emoldura um determinado texto, estando diretamente nele inserido, como capa, título do livro, títulos e subtítulos de capítulos, imagens, prefácios, epígrafes, dedicatórias etc.; e como elementos "epitextuais", todos os dados relacionados ao texto-base, mas que lhe sejam exteriores, como entrevistas do autor, depoimentos, sua correspondência etc. Essas duas categorias juntas formam o que Genette chama de "paratexto".

\section{Referências}

ABREU, C. F. Oásis. In: O ovo apunhalado. Porto Alegre: Globo, 1975. p.1824.

. Cartas. Organização de Italo Moriconi. Rio de Janeiro: Aeroplano, 2002.

CALLEGARI, J. Caio Fernando Abreu - Inventário de um escritor irremediável. São Paulo: Seoman, 2008.

COLONNA, V. Autofiction \& autres mythomanies littéraires. Auch Cedex (France): Éditions Tristram, 2004.

DOUBROVSKY, S. Les points sur ler “i”. In: JEANNELLE, J.-L.; VIOLLET, C. (Dir.) Genèse et autofiction. Louvain-la-Neuve: Bruylant-Academia, 2007. p.54-65.

ECO, U. Protocolos ficcionais. In: . Seis passeios pelos bosques da ficção. São Paulo: Cia. das Letras, 2006. p.123-47.

GENETTE, G. Senils. Paris: Seuil, 1987.

GRELL, I. Pourquoi Serge Doubrovsky n'a pu éviter le terme d'autofiction. In: JEANNELLE, J. L.; VIOLLET, C. (Dir.) Genèse et autofiction. Louvain-la-Neuve: BruylantAcademia, 2007. p.39-51.

LEJEUNE, P. Signes de vie. Le pacte autobiographique 2. Paris: Seuil, 2005.

PEN, M. Quem tem medo de Caio F.? In: ABREU, C. F. Caio 3D. O essencial da década de 990. Rio de Janeiro: Agir, 2006.

PERRONE-MOISÉS, L. A criação do texto literário. In: Flores da escrivaninha. São Paulo: Cia. das Letras, 1990.

SÜSSEKIND, F. Censura: uma pista dupla. In: Literatura e vida literária. Polêmicas, diários \& retratos. Belo Horizonte: Editora da UFMG, 2004. p.17-47. 
RESUMO - O artigo apresenta uma leitura da obra do escritor Caio Fernando Abreu (1948-1996, identificando em sua escrita uma estrutura autoficcional em que se congregam elementos reais e ficcionais articulados e entrelaçados por uma construção linguística literária. Analisa-se sob esse aspecto um conto do livro $O$ ovo apunbalado considerando-se que a obra de Caio F. apresenta essa configuração desde os seus primeiros textos, vindo a tornar-se um dos elementos determinantes de sua escrita ficcional.

PALAVRAS-CHAVE: Autoficção, Imagem e memória, Fiç̧ão e realidade, Autobiografia.

ABSTRACT - The article presents a reading of Caio Fernando Abreu's work (1948-1996) that identifies in his writing an auto-fictional structure in which real and fictional elements are combined and entwined through a linguistic literary construction. One of the short stories of his book O ovo apunbalado is analyzed through this point of view. It is taken in consideration the fact that Caio F's works present this configuration since his first texts, which then became a constant element in his fictional writing.

KEYWORDS: Auto-fiction, Image and memory, Fiction and reality, Autobiography.

Nelson Luis Barbosa é doutor em Letras pelo Departamento de Teoria Literária e Literatura Comparada da Faculdade de Filosofia, Letras e Ciências Humanas da Universidade de São Paulo (FFLCH-USP). @ - nelsonlb@uol.com.br

Recebido em 24.2.2011 e aceito em 4.3.2011. 